\title{
The Role of Plasmapheresis in Critical Illness
}

\author{
Trung C. Nguyen, M.D ${ }^{1,2}$, Joseph E. Kiss, M.D ${ }^{3}$, Jordana R. Goldman, M.D ${ }^{1}$, and Joseph A. \\ Carcillo, M.D. ${ }^{4}$ \\ ${ }^{1}$ Section of Critical Care Medicine, Department of Pediatrics, Baylor College of Medicine/Texas \\ Children's Hospital, Houston, TX \\ ${ }^{2}$ Division of Thrombosis Research, Department of Medicine, Baylor College of Medicine, \\ Houston, TX \\ ${ }^{3}$ The Institute of Transfusion Medicine, Division of Hematology/Oncology, Department of \\ Medicine, University of Pittsburgh School of Medicine, Pittsburgh, PA \\ ${ }^{4}$ Departments of Critical Care Medicine and Pediatrics, Univeristy of Pittsburgh School of \\ Medicine, Pittsburgh, PA
}

\section{Synopsis}

In this chapter, we will review the current recommendations from the American Society for Apheresis regarding the use of plasmapheresis in many of the diseases that intensivists commonly encounter in critically ill patients. Recent experience indicates that therapeutic plasma exchange (TPE) may be useful in a wide spectrum of illnesses characterized by microvascular thrombosis, the presence of auto-antibodies, immune activation with dysregulation of immune response, and in some infections.

\section{Keywords}

therapeutic plasma exchange; thrombotic microangiopathy; microvascular thrombosis; autoantibodies; liver failure; hemophagocytic lymphohistiocytosis; rapidly progressive glomerulo nephritis; vasculitides; solid organ transplantation

\section{Introduction}

Since antiquity, mankind has hypothesized there are bad substances called "humors" which accumulate in the blood of sick patients and that the removal of these humors would make

\footnotetext{
(C) 2012 Elsevier Inc. All rights reserved.

Corresponding Author: Trung Nguyen, MD, Assistant Professor, Section of Critical Care Medicine, Baylor College of Medicine/ Texas Children's Hospital, 6621 Fannin, WT6-006, Houston, Texas 77030, Ph (832) 826-6226, Fax (832) 825-6229; tcnguyen@texaschildrenshospital.org.

Publisher's Disclaimer: This is a PDF file of an unedited manuscript that has been accepted for publication. As a service to our customers we are providing this early version of the manuscript. The manuscript will undergo copyediting, typesetting, and review of the resulting proof before it is published in its final citable form. Please note that during the production process errors may be discovered which could affect the content, and all legal disclaimers that apply to the journal pertain.

${ }^{1}$ The American Society of Apheresis published a comprehensive evidence-based guideline to aid intensivists in using plasmapheresis as a therapeutic strategy

${ }^{2}$ Plasmapheresis has seen an increase in usage in critically ill patients

${ }^{3}$ Thrombotic microangiopathies, vasculitides, liver failure, $\mathrm{ABO}$ incompatible solid organ transplantation, neurologic disorders, renal disorders, and immune dysregulation are some of the disorders that intensivists could consider using plasmapheresis as a therapeutic strategy
} 
patients feel better. Bloodletting, the practice of draining blood from sick patients, has been around since the Egyptians, dating back one thousand years B.C. The practice of bloodletting peaked in the $18^{\text {th }}$ century and evolves with modern technology to this day. Blood has four major components: red blood cells, white blood cells, platelets, and plasma. With modern machinery, blood can be separated into each of these four components. Thus, if a particular blood component is causing harm, it can be selectively removed and replaced with the same blood component from healthy donors.

In this chapter, we will review the current recommendations from the American Society for Apheresis for plasmapheresis in many of the diseases that intensivists commonly encounter in critically ill patients. ${ }^{1}$ Apheresis is derived from the Greek word "aphairesis" - to take away. Plasmapheresis is an apheresis procedure that separates and removes the plasma component from a patient. Plasma exchange is when plasmapheresis is followed by replacement with fresh frozen plasma infusion.

\section{Techniques of Separating Plasma from Whole Blood}

Plasmapheresis is performed by two fundamentally different techniques: centrifugation or filtration. With centrifugation apheresis, whole blood is spun so that the four major blood components are separated out into layers by their different densities. With filtration plasmapheresis, whole blood passes through a filter to separate the plasma components from the larger cellular components of red blood cells, white blood cells, and platelets. Centrifugation apheresis is commonly performed by blood bankers. A major advantage is that there is no limit on the size of the molecules being removed. Its disadvantage is that it usually requires a consultation to another service such as a blood banker. Filtration plasmapheresis is commonly performed by nephrologists and intensivist. Its major advantage is that a large filter can be easily added to the existing continuous veno-venous hemodialysis circuit without much interruption to patient care. However, a disadvantage is that the size of the molecules removed is limited by the size of the pore of the filter. This is problematic because certain plasma molecules are larger than existing available filters, for example the ultra-large von Willebrand factor multimers can measure up to 12 million daltons.

\section{Plasmapheresis/Plasma Exchange in Critically III Patients}

In 2010, The American Society for Apheresis (ASFA) published its updated comprehensive "Guideline on the Use of Therapeutic Apheresis in Clinical Practice-Evidence-Based Approach". ${ }^{1}$ The society divided its recommendations into four categories:

- Category I: "Disorder for which apheresis is accepted as first-line therapy, either as a primary standalone treatment or in conjunction with other modes of treatment".

- Category II: "Disorders for which apheresis is accepted as second-line therapy, either as a standalone treatment or in conjunction with other modes of treatment".

- Category III: "Optimum role of apheresis therapy is not established. Decision making should be individualized".

- Category IV: "Disorders in which published evidence demonstrates or suggests apheresis to be ineffective or harmful. Internal Review Board approval is desirable if apheresis treatment is undertaken in these circumstances".

This chapter reviews many of the diseases in critically ill patients that plasmapheresis/ therapeutic plasma exchange (TPE) may play a role in the therapeutic strategy. 


\section{Thrombotic Microangiopathies}

Thrombotic microangiopathies are syndromes associated with disseminated microvascular thrombosis. ${ }^{2}$ Clinically, these syndromes manifest as new onset thrombocytopenia and if untreated, will lead to multiple organ failure and death. Thrombotic Thrombocytopenic Purpura (TTP), Hemolytic Uremic Syndrome (HUS), Disseminated Intravascular Coagulation (DIC) and Catastrophic Antiphospholipid Syndrome (CAPS) are different spectrums of thrombotic microangiopathies. The ASFA gives a category I recommendation for plasmapheresis/therapeutic plasma exchange (TPE) in patients with TTP and atypical HUS due to autoantibody to factor $\mathrm{H}$, category II recommendation for TPE in patients with CAPS, and a category III recommendation for TPE in patients with Hematopoietic Stem Cell Transplant - Associated Thrombotic Microangiopathy. ${ }^{1}$

\section{Thrombotic Thrombocytopenic Purpura (TTP)}

The classic "pentad" of TTP is composed of: thrombocytopenia, microangiopathic hemolytic anemia, neurologic abnormalities, renal failure, and fever. The underlying pathophysiologic process of TTP is the deficiency of ADAMTS-13 (a.k.a. von Willebrand factor (VWF) -cleaving proteinase) leading to uncleaved thrombogenic large and ultra-large VWF. $^{2}$ Autopsies on patients who died from TTP demonstrate distinctive VWF- and platelet-rich microthrombi. ${ }^{3-6}$ There are two forms of TTP, congenital and acquired. In the congenital form, there is a genetic abnormality in ADAMTS- $13 .{ }^{7}$ In the acquired form, ADAMTS- 13 inhibitors and/or proteolytic inactivators are present in the plasma. ${ }^{8,9}$ There is a growing list of ADAMTS-13 inhibitors and proteolytic inactivators including interleukin-6, plasma-free hemoglobin, IgG auto-antibody, Shiga toxin, plasmin, thrombin, and granulocyte elastase. ${ }^{9-14}$ TPE has been shown in a large randomized controlled trial to significantly improve survival compared to plasma infusion. ${ }^{15}$ The ASFA gives a category I recommendation for TPE in TTP. ${ }^{1}$

TPE is thought to remove the large and ultra-large VWF, remove the ADAMTS-13 inhibitors and proteolytic inactivators, and replenish ADAMTS- $13 .{ }^{2}$ Because the underlying pathology is the deficiency of ADAMTS-13, the recommended TPE replacement fluid is plasma or plasma with cryoprecipitate removed (i.e. the plasma portion that is depleted with ultra-large VWF and large plasma VWF).

\section{Typical Hemolytic Uremic Syndrome (HUS)}

The "triad" of HUS is thrombocytopenia, microangiopathic hemolytic anemia, and renal failure. ${ }^{2}$ This syndrome is divided into typical HUS and atypical HUS. Typical HUS, which accounts for $85-90 \%$ of all HUS, is commonly associated with infection and diarrhea. ${ }^{16,17}$ Shiga toxin-producing Escherichia coli 0157:H7 accounts for the majority of typical HUS with a mortality of $<5 \%$. Shiga toxin has been shown in vitro to 1) induce ultra-large VWF to be released from endothelium, and 2) inhibit ADAMTS-13, similar to the pathophysiology of TTP. However, clinical association studies have not consistently shown severe ADAMTS-13 deficiency in Escherichia coli 0157:H7-induced HUS. ${ }^{6}$ Certain neuramidase producing-bacteria, such as Streptococcus pneumonia, account for a minority of typical HUS and has a higher mortality when compared to that of typical HUS with a mortality rate of $19-50 \%$. Neuramidase has been shown to cleave sialic acid residues from cell surface protein exposing the Thomsen-Freidenreich (T-) antigen. HUS occurs when endogenous IgM directed against the T-antigen binds to the exposed T-antigen on endothelium, red blood cells, and platelets resulting in platelet-rich thrombi formation in the microvasculature. Currently, the ASFA does not recommend TPE (category IV) for typical HUS. $^{1}$ 


\section{Atypical Hemolytic Uremic Syndrome}

In atypical HUS, in addition to the typical "triad" of signs and symptoms, patients have neurologic abnormalities beyond that of the usual "irritability" seen in most children with typical HUS. Investigation into pathophysiology of atypical HUS has identified two different processes, genetic abnormalities or acquired autoantibodies. Currently, it is thought that up to $60 \%$ of patients with atypical HUS have genetic abnormalities in the complement pathway. ${ }^{17}$ Autoantibodies against factor $\mathrm{H}$ have been observed in up to $10 \%$ of patients with atypical HUS. ${ }^{17}$ In either case, there is uncontrolled activation of the alternative complement pathway, resulting in direct injury to the microvasculature. Atypical HUS has a reported mortality rate of $25 \% .{ }^{17}$

The ASFA gives a category I recommendation for TPE in atypical HUS due to autoantibody to factor $\mathrm{H} .{ }^{1}$ Factor $\mathrm{H}$ regulates and inhibits the alternative pathway of the complement pathway. TPE is thought to remove the autoantibody to factor $\mathrm{H}$ and normalize complement activities. ${ }^{18}$

The ASFA gives a category II recommendation for TPE in atypical HUS due to complement factor gene mutations. ${ }^{1}$ These genes include inhibitors of alternative complement pathways such as factor $\mathrm{H}$, factor I, membrane cofactor protein, complement factor H-related proteins, and $\mathrm{C} 4 \mathrm{~b}$ binding protein. Gain-of-function mutations for alternative complement pathways also been described such as factor $\mathrm{B}$, and $\mathrm{C} 3 .^{17}$

During the first 24-72 hours of a patient presenting with the "triad" of signs and symptoms, along with neurologic abnormalities, most clinicians are not able to differentiate TTP from atypical HUS, nor differentiate atypical HUS due to autoantibody to factor $\mathrm{H}$ from atypical HUS due to complement factor gene mutations. The authors of this chapter recommend consulting nephrology and hematology to send the appropriate ADAMTS-13, VWF and complement studies. In addition, TPE should be initiated until the results of biomarkers can differentiate the diagnoses. Because the underlying pathology is the deficiency of complement $\mathrm{H}$ activity, the recommended TPE replacement fluid is either plasma or albumin. The authors of this article recommend plasma as the replacement fluid since it has normal Factor $\mathrm{H}$ activity.

\section{Disseminated Intravascular Coagulation (DIC)}

DIC is characterized by intravascular activation of coagulation leading to the consumption and exhaustion of coagulation proteins and platelets. Autopsies in patients who died with DIC reveal extensive fibrin deposition in small and mid-size vessels in all organs. $3,4,6,19$ One of the proposed mechanisms for DIC is that systemic inflammation, such as occurs in sepsis, activates leukocytes and endothelium. These cells then synthesize, express, and release tissue factor. Tissue factor forms a complex with factor VII leading to the activation of coagulation and the resultant disseminated microvascular thrombosis with fibrin-rich microthrombi. ${ }^{20}$ Clinically, these patients present with shock and in a prothrombotic and antifibrinolytic state with subsequent bleeding diathesis. Many case series and observational studies suggest that TPE might have a beneficial effect in DIC. ${ }^{21-25}$ TPE is thought to normalize the blood coagulation to homeostasis milieu by removing tissue factor and plasminogen activator inhibitors-type-I, and by replacing antithrombin III, protein $\mathrm{C}$, and coagulation factors. Currently, the ASFA does not have a specific recommendation for TPE in DIC.

However, the ASFA gives a category III recommendation for TPE in Sepsis with Multiorgan Failure. ${ }^{1}$ Large trials have documented that sepsis can induce thrombotic microangiopathy, and in particular, sepsis-induced DIC is present in $30-50 \%$ of patients with severe sepsis. ${ }^{19,26}$ DIC has been shown to be one of the major contributing 
mechanisms to multiple organ failure in critically ill patients. ${ }^{19}$ Thus, there is a biologic plausibility that the beneficial treatment effect of TPE in Sepsis with Multiorgan Failure could be from reversing DIC.

\section{Thrombocytopenia-Associated Multiple Organ Failure (TAMOF)}

Recently, investigators observed that pediatric patients with Thrombocytopenia-Associated Multiple Organ Failure (TAMOF) have thrombotic microangiopathy and that TPE may have a beneficial effect. ${ }^{25}$ These investigators reported that pediatric patients with new onset thrombocytopenia defined as platelet counts $<100,000 / \mathrm{mm}^{3}$ and at least 3 failing organs have a pathophysiologic process similar to that of TTP such as low ADAMTS-13 activities, presence of ultra-large VWF, and high VWF activities. A subset of TAMOF patients also had prolonged prothrombin time suggesting fibrin pathway activation, as in DIC. On autopsies, pediatric TAMOF patients have VWF-rich and platelet-rich microthrombi similar to patients with TTP, and also fibrin-rich microthrombi similar to patients with DIC. In a small single center trial, they reported that TPE had a significant beneficial treatment effect in reducing organ failure score (Pediatric Logistic Organ Dysfunction) and mortality. Of note, all of these patients had concurrent sepsis. Thus, the ASFA category III recommendation for TPE in Sepsis with Multiorgan Failure, ${ }^{1}$ as discussed above, encompasses sepsis-induced TAMOF.

A larger multi-center registry of TPE in pediatric TAMOF is in its analysis phase. Hopefully, this registry will shed more light on the treatment effect of TPE for TAMOF. Because the underlying pathology could be in part from deficient coagulation factors due to consumption, the recommended TPE replacement fluid is either plasma or albumin. The authors of this article recommend plasma as the replacement fluid.

\section{Catastrophic Antiphospholipid Syndrome (CAPS)}

The underlying pathology in CAPS is an acquired hypercoagulable state due to the presence of antiphospholipid, anticardiolipin, and/or anti-beta 2 glycoprotein I antibodies. ${ }^{27}$ The clinical presentation is acute microvascular venous and arterial thrombosis leading to multiple organ failure. Currently, the definition of CAPS includes 1) involvement of at least 3 organs, 2) manifestation in less than one week, 3) confirmed histopathology of small vessel occlusion in one tissue, and 4) presence of antiphospholipid antibodies. ${ }^{28}$ This syndrome may be clinically indistinguishable from TTP, HUS, DIC, and TAMOF. For example, overt DIC is present in $20 \%$ of patients with CAPS. Biomarkers could help to differentiate between CAPS from TTP, HUS, and DIC.

The ASFA gives a category II recommendation for TPE in CAPS. ${ }^{1}$ TPE is thought to remove antiphospholipid antibodies, inflammatory cytokines, and complement, and to replace the deficient coagulation factors. ${ }^{29-31}$ The recommended TPE replacement fluid is plasma as it has normal level of coagulation proteases.

\section{Hematopoietic Stem Cell Transplant - Associated Thrombotic Microangiopathy}

The causes of thrombotic microangiopathy in hematopoietic stem cell transplant are unclear. ${ }^{32-35}$ Endotheliopathy is suggested to be the underlying pathophysiologic process. ${ }^{36}$ However, it is postulated that there could be multiple triggers including high-dose conditioning chemotherapy, irradiation, graft-versus-host disease (GVHD), mammalian target of rapamycin (mTOR) and calcineurin inhibitor drugs, and infection. The mainstay of therapy involves treating GVHD, reducing doses of the mTOR and calcineurin inhibitor drugs, and treating infection. ADAMTS-13 activities have been shown to be low normal in these patients. Some patients seem to respond to TPE. Thus, a trial of TPE with a defined 
endpoint in selected patients with persistent thrombotic microangiopathy might be considered. ${ }^{37-39}$

The ASFA gives a category III recommendation for TPE in Hematopoietic Stem Cell Transplant - Associated Thrombotic Microangiopathy. ${ }^{1}$ The recommended TPE replacement fluid is plasma or plasma with cryoprecipitate removed.

\section{Thrombotic Microangiopathy: Drug-Associated}

A number of drugs have been shown to activate platelets and/or cause endotheliopathy. Antiplatelet drugs such as ticlopidine and clopidogrel are members of the thienopyridine class of drugs which inhibit the adenosine diphosphate (ADP) receptor/P2Y12 on platelets. They have been shown to induce TTP-like pathophysiology with low ADAMTS-13 activities and clinical signs of thrombotic microangiopathy in rare cases. ${ }^{40-42}$ Calcineurin inhibitors such as cyclosporine and tacrolimus have been reported to induce endotheliopathy progressing to thrombotic microangiopathy. ${ }^{43-46}$ Management includes either stopping the offending drug or, if this is not an option, at least reducing the drug intake. TPE is thought to be beneficial similar to its use in acquired TTP.

The ASFA gives a category I recommendation for TPE in ticlopedine or clopidogrel and category III for TPE in cycloporine or tacrolimus-Associated Thrombotic Microangiopathy. ${ }^{1}$ The recommended TPE replacement fluid is plasma or plasma with cryoprecipitate removed.

\section{Vasculitides}

\section{Catastrophic Antiphospholipid Syndrome (CAPS)}

This syndrome is often grouped with vasculitides as it is diagnosed by rheumatologists. However, CAPS is a thrombotic microangiopathy and has significant overlap with TTP, HUS, DIC and TAMOF. Please refer to the above section of Thrombotic Microangiopathies for a review of CAPS.

\section{Systemic Lupus Erythematosus (SLE)}

SLE is an autoimmune disorder that causes chronic inflammation due to circulating autoantibodies, immune complexes and complement deposition. SLE is much more common in women than in men. Clinical symptoms such as malaise, arthritis, rash and fever, are nonspecific and often vary from person to person. However, severe progression of disease can occur with involvement of virtually any organ with consequent manifestations such as stroke, renal failure, pulmonary hemorrhage, myocarditis, hemolytic anemia, and pulmonary embolism. Confirmatory tests include the presence of specific anti-nuclear antibodies such as anti-double stranded DNA and anti-Smith antibodies. First line therapy includes antiinflammatory and immunosuppressive agents. However, when severe SLE presents with cerebritis or pulmonary hemorrhage, TPE is recommended. ${ }^{4-50}$

The ASFA gives a category II recommendation for TPE in severe SLE such as with cerebritis or diffuse alveolar hemorrhage. ${ }^{1}$ The ASFA does not recommend TPE (category IV) for SLE-associated nephritis. TPE is thought to remove auto-antibodies, complement, interferon alpha, and immune complexes. ${ }^{51,52}$ The recommended TPE replacement fluid is either plasma or albumin. 


\section{Liver failure}

\section{Wilson's disease in fulminant hepatic failure with hemolysis}

Wilson's disease is an autosomal recessive genetic disorder that results in excessive accumulation of copper in the liver, brain, cornea, kidney and heart. ${ }^{53}$ The genetic mutation is on the ATP7B gene, which codes for P-type ATPase (cation transport enzyme). This leads to impaired biliary copper excretion and linkage of copper to ceruloplasmin, a coppercarrying protein. As copper continues to accumulate in the liver, patients may present with asymptomatic elevation of liver enzymes, hepatitis, cirrhosis or with fulminant liver failure. These patients may also present with hemolytic anemia due to copper inhibition of red blood cells energy metabolism or direct damage to the cell membrane. When patients with Wilson's disease present with fulminant liver failure, it is thought that a significant amount of copper is released from necrotic hepatocytes. Plasma-free copper then causes rapid destruction of red cells which leads to rapid release of plasma-free hemoglobin. Elevated plasma-free hemoglobin has been shown to cause oxidative stress, nitric oxide depletion, endotheliopathy, microvascular thrombosis, and multiple organ failure. The only definite therapy is liver transplantation. However, without aggressive support, the patient is at risk of succumbing prior to liver transplantation.

The ASFA gives a category I recommendation for TPE in Fulminant Hepatic Failure with Hemolysis. ${ }^{1}$ TPE is thought to provide rapid removal of plasma-free copper and hemoglobin. ${ }^{54-58}$ The recommended TPE replacement fluid is plasma.

\section{Acute fulminant liver failure}

Acute fulminant liver failure has many causes and can develop from previously healthy liver or from chronic liver failure ${ }^{59}$ The liver has four major functions including protein synthesis, toxin clearance, gluconeogenesis/glycolysis, and biliary clearance. When the functions of protein synthesis and toxin clearance are severely compromised, severe clinical deterioration ensues. The liver synthesizes most of the major coagulation proteases. Without these, patients may develop severe coagulopathy and are at high risk of spontaneous hemorrhages, especially in the brain. In addition, patients are also at high risk for developing severe cerebral edema due to accumulation of toxins such as ammonia, endogenous benzodiazepines, and aromatic amino acids etc... ${ }^{60,61}$ If there is no spontaneous recovery of liver function, patients will require liver transplantation. Currently, there are no U.S. Food and Drug Administration approved liver-support devices. Clinicians are only able to provide supportive care for these patients such as transfusion of blood products, securing the airway for hepatic coma, providing medical support for increase intracranial pressure, providing hemodynamic support and appropriate antibiotics. These strategies, however, do not address the accumulation of toxins in the plasma. Furthermore, large amount of blood product transfusions and the commonly associated hepato-renal syndrome will inevitably lead to severe fluid overload. TPE is thought to remove the accumulation of toxins in the plasma and to restore coagulation back to its homeostasis milieu without fluid overloading the patients. ${ }^{60,62-64}$

The ASFA gives a category III recommendation for TPE in Acute Liver Failure. ${ }^{1}$ The recommended TPE replacement fluid is plasma or mixed plasma and albumin.

\section{Solid Organ Transplantations}

\section{ABO Incompatible Solid Organ Transplantation}

Due to shortage of available organs and especially ABO-matched organs, ABO

incompatible organs are now frequently used in transplantation. During and after an ABO- 
incompatible solid organ transplantation, the recipient's natural anti-bodies to the A and/or $\mathrm{B}$ antigen on the donated organ will start to cause destruction of the newly grafted organ. ${ }^{65}$ This might present as a hyperacute or acute humoral rejection. The mainstay of therapy has been immunosuppression. However, with the adjunct of TPE during the pre-and posttransplantation periods, along with immunosuppression and intravenous immunoglobulin (IVIG), survival of ABO-incompatible organs is comparable to those of ABO matched organs.

The ASFA gives a category II recommendation for TPE in ABO Incompatible Heart $(<40$ months of age) and Kidney, and a Category III recommendation for ABO Incompatible Liver (liver perioperative). ${ }^{1}$ The goal is to decrease the $\mathrm{IgG}$ and IgM titers to $\leq 8$ in liver and $<4$ in kidney and heart transplantations. ${ }^{66-68}$ For liver transplants, antibody titer of $<8$ should be aimed for 2 weeks post-transplant. For kidney transplants, the goal should be antibody titer is $<8$ during the 1 st week and $<16$ during the $2^{\text {nd }}$ week. ${ }^{69,70}$ The recommended TPE replacement fluid is either albumin or plasma. For liver transplantation, plasma should be considered if there is significant coagulopathy.

\section{Neurological Disorders}

The ASFA gives strong recommendations (categories I and II's) for TPE in critically ill patients with a variety of primary neurological disorders. ${ }^{1}$ The proposed mechanism of these disorders seems to stem from molecules (i.e. auto-antibodies) that have developed in the patient's plasma that cause injuries to the central and/or peripheral nervous systems. These patients often present with focal neurologic deficits and may progress to generalized devastating neurologic injuries. For example, these patients may present with gross or fine motor weakness progressing to paralysis, hyporeflexia progressing to areflexia, paresthesia, pain, cranial nerve deficit, seizures, strokes, autonomic dysfunction, and neuropsychiatric symptoms. TPE is often utilized by the clinicians when a short trial of steroids, cytotoxic agents and/or IVIG has been unsuccessful in halting the progression of signs and symptoms. ${ }^{71-75}$

The ASFA gives a category I recommendation for TPE in Acute Inflammatory Demyelinating Polyneuropathy (Guillain-Barre Syndrome), Chronic Inflammatory Demyelinating Polyradiculoneuropathy (CIDP), Pediatric Autoimmune Neuropsychiatric Disorders Associated with Streptococcal Infections and Sydenham's Chorea (PANDAS), Multiple Sclerosis, and Myasthenia Gravis. The ASFA gives a category II recommendation for TPE in Acute Disseminated Encephalomyelitis, Neuromyelitis Optica, Chronic Focal Encephalitis (Rasmussen's Encephalitis), and Lambert-Eaton Myasthenic syndrome. ${ }^{1}$

TPE is thought to remove auto-antibodies to various components of the neurologic system:

- myelin in Guillain-Barre, CIDP, Multiple Sclerosis, and Acute Disseminated Encephalomyelitis;

- neurons in the basal ganglia in PANDAS;

- acetylcholine receptor on the post-synaptic surface of the motor end plate in Myasthenia Gravis;

- aquaporin-4, a water channel on astrocyte foot process at the blood brain barrier in Neuromyelitis Optica;

- glutamate receptor GluR3 in Rasmussen's Encephalitis;

- voltage gated calcium channel of the pre-synaptic neuron in Lambert-Eaton Myasthenic syndrome. ${ }^{71,74,76,77}$ 
Because the underlying problem is the presence of pathologic auto-antibodies and not the deficiency of plasma molecules, the recommended TPE replacement fluid is albumin.

\section{Renal \\ Rapidly Progressive Glomerulonephritis (RPGN)}

RPGN encompasses three distinct histopathologic processes of glomerular crescent formation in at least $50 \%$ of glomeruli seen in renal biopsies. Clinically, these patients might present with a rapid course of renal failure. Therapy involves a combination of steroids and anti-cytotoxic agents. TPE is considered when these patients present critically ill and in particular, with pulmonary hemorrhage. The recommendation for TPE is also dependent on the histopathologic process.

\section{Type I RPGN: Anti-Glomerular Basement Membrane Disease (Goodpasture's Syndrome)}

Histopathology of this entity reveals linear deposits of $\operatorname{IgG}$ to the non-collagenous domain (NC1) of the alpha-3 chain of collagen type IV in the glomerular basement membrane. The ASFA gives a category I recommendation for TPE in Anti-Glomerular Basement Membrane disease with diffuse alveolar hemorrhage and/or with dialysis independence. ${ }^{1}$ The ASFA does not recommend (category IV) TPE for this entity with dialysis dependence and without diffuse alveolar hemorrhage. ${ }^{1}$ Case series have shown that TPE in those with creatinine < $6.6 \mathrm{mg} / \mathrm{dL}$ had recovery of kidney function, whereas those with creatinine $>6.6 \mathrm{mg} / \mathrm{dL}$ did not. The recommended TPE replacement fluid is albumin, but if pulmonary hemorrhage is present, then plasma is recommended. ${ }^{78-81}$

\section{Type II RPGN: Immune Complex Rapidly Progressive Glomerulonephritis}

Histopathology of this entity reveals granular deposits of immune complexes from a wide range of causes including post-streptococcal glomerulonephritis, membranoproliferative glomerulonephritis, lupus nephritis, IgA nephropathy, and Henoch-Schonlein purpura. ${ }^{82,83}$ The ASFA gives a category III recommendation for TPE in Immune Complex RPGN. ${ }^{1}$ The recommended TPE replacement fluid is albumin.

\section{Type III RPGN: Anti-Neutrophil Cytoplasmic Anti-bodies (ANCA) - Associated RPGN (Wegener's Granulomatosis)}

Histopathology of this entity reveals minimal immune deposits in the glomerulus. However, the serum contains the distinctive biomarker ANCA. The ASFA gives a category I recommendation for TPE in ANCA-associated RPGN with diffuse alveolar hemorrhage and/ or with dialysis dependence, and a category III for those with dialysis independence. ${ }^{1}$ The recommended TPE replacement fluid is albumin but, if pulmonary hemorrhage is present, then plasma is recommended. ${ }^{84-87}$

\section{Other Conditions}

\section{Hemophagocytic Lymphohistiocytosis: Pathologic Hyperactive Inflammation}

Secondary Hemophagocytic Lymphohistiocytosis (HLH) has been increasingly diagnosed in the intensive care unit. HLH is a syndrome of pathologic hyperactive inflammation due to unchecked immune activation. ${ }^{88}$ Primary HLH is associated with genetic mutations such as those in the perforin gene. Perforin is normally secreted from cytotoxic T-lymphocytes and natural killer cells into the membrane of target cells and acts to trigger cell death. HLH occurs when lymphocyte-mediated cytotoxicity is impaired and apoptosis is unable to be triggered. This leads to abnormal T-cell activation and pathologic inflammatory cytokine production. Clinically these patients progress to multiple organ failure with the following clinical criteria: 1) fever; 2) splenomegaly; 3) cytopenia; 4) hypertriglyceridemia; 5) 
hemophagocytosis in bone marrow, spleen, lymph nodes, or liver; 6) low or absent NK-Cell activity; 7) Ferritin > $500 \mathrm{ng} / \mathrm{mL}$, and 8) elevated serum CD 25 (alpha-chain of soluble IL-2 receptor). ${ }^{88,89}$ The primary treatment for familial/primary HLH is a course of immunosuppression and bone marrow transplantation. Secondary HLH is an acquired form of pathologic hyperactive inflammation due to a trigger. Epstein Barr Virus is the most commonly recognized infection associated with secondary HLH. For other associated viral, bacterial and fungal infections, the line between secondary HLH versus sepsis-induced multiple organ failure due to other mechanisms, such as immune paralysis with unresolved infection and thrombotic microangiopathy, is blurred. ${ }^{90}$ Much research is still needed to define the best strategy to balance the immune modulation. Too much immune suppression in an immune paralyzed patient with unresolved infection could be detrimental. Inadequate immune suppression in an uncontrolled pathologic hyperactive inflammation (i.e. secondary HLH) could also be detrimental.

TPE has been reported in many small case series to be beneficial in calming the cytokine storm and to provide hematologic support in patients with primary and secondary HLH. ${ }^{91-99}$ A recent small study found significant improved survival in patients with secondary HLH who received plasma exchange, steroids, and IVIG $(n=17)$ versus those who received plasma exchange, steroids, and/or cyclosporine, and/or etoposide $(n=6) .{ }^{100}$ Currently, the ASFA has not commented on the use of TPE in HLH. Further research is warranted for this difficult therapeutic strategy.

\section{Conclusions}

TPE is a modern approach to the ancient therapy of bloodletting. Recently, the American Society for Apheresis, using an evidence-based approach, published a comprehensive apheresis guideline to aid physicians caring for critically ill patients who depend on plasmapheresis as a therapeutic strategy. We are indebted to them for their hard work. It seems that TPE as a therapy has seen an increase in usage, particularly by those who take care of critically ill patients. Using an evidence-based approach is the best way to standardize care and also to provide a platform for innovation to move the field forward.

\section{References}

1. Szczepiorkowski ZM, Winters JL, Bandarenko N, et al. Guidelines on the use of therapeutic apheresis in clinical practice--evidence-based approach from the Apheresis Applications Committee of the American Society for Apheresis. J Clin Apher. 2010; 25(3):83-177. [PubMed: 20568098]

2. Moake JL. Thrombotic microangiopathies. N Engl J Med. 2002; 347(8):589-600. [PubMed: 12192020]

3. Asada Y, Sumiyoshi A, Hayashi T, Suzumiya J, Kaketani K. Immunohistochemistry of vascular lesion in thrombotic thrombocytopenic purpura, with special reference to factor VIII related antigen. Thromb Res. 1985; 38(5):469-479. [PubMed: 2861671]

4. Burke AP, Mont E, Kolodgie F, Virmani R. Thrombotic thrombocytopenic purpura causing rapid unexpected death: value of CD61 immunohistochemical staining in diagnosis. Cardiovasc Pathol. 2005; 14(3):150-155. [PubMed: 15914300]

5. Hosler GA, Cusumano AM, Hutchins GM. Thrombotic thrombocytopenic purpura and hemolytic uremic syndrome are distinct pathologic entities. A review of 56 autopsy cases. Arch Pathol Lab Med. 2003; 127(7):834-839. [PubMed: 12823037]

6. Tsai HM, Chandler WL, Sarode R, et al. von Willebrand factor and von Willebrand factor-cleaving metalloprotease activity in Escherichia coli O157:H7-associated hemolytic uremic syndrome. Pediatr Res. 2001; 49(5):653-659. [PubMed: 11328948]

7. Levy GG, Nichols WC, Lian EC, et al. Mutations in a member of the ADAMTS gene family cause thrombotic thrombocytopenic purpura. Nature. 2001; 413(6855):488-494. [PubMed: 11586351] 
8. Furlan M, Robles R, Galbusera M, et al. von Willebrand factor-cleaving protease in thrombotic thrombocytopenic purpura and the hemolytic-uremic syndrome. N Engl J Med. 1998; 339(22): 1578-1584. [PubMed: 9828245]

9. Tsai HM, Lian EC. Antibodies to von Willebrand factor-cleaving protease in acute thrombotic thrombocytopenic purpura. N Engl J Med. 1998; 339(22):1585-1594. [PubMed: 9828246]

10. Bernardo A, Ball C, Nolasco L, Moake JF, Dong JF. Effects of inflammatory cytokines on the release and cleavage of the endothelial cell-derived ultralarge von Willebrand factor multimers under flow. Blood. 2004; 104(1):100-106. [PubMed: 15026315]

11. Crawley JT, Lam JK, Rance JB, Mollica LR, O'Donnell JS, Lane DA. Proteolytic inactivation of ADAMTS13 by thrombin and plasmin. Blood. 2005; 105(3):1085-1093. [PubMed: 15388580]

12. Studt JD, Hovinga JA, Antoine G, et al. Fatal congenital thrombotic thrombocytopenic purpura with apparent ADAMTS13 inhibitor: in vitro inhibition of ADAMTS13 activity by hemoglobin. Blood. 2005; 105(2):542-544. [PubMed: 15367436]

13. Nolasco LH, Turner NA, Bernardo A, et al. Hemolytic uremic syndrome-associated Shiga toxins promote endothelial-cell secretion and impair ADAMTS13 cleavage of unusually large von Willebrand factor multimers. Blood. 2005; 106(13):4199-4209. [PubMed: 16131569]

14. Ono T, Mimuro J, Madoiwa S, et al. Severe secondary deficiency of von Willebrand factorcleaving protease (ADAMTS13) in patients with sepsis-induced disseminated intravascular coagulation: its correlation with development of renal failure. Blood. 2006; 107(2):528-534. [PubMed: 16189276]

15. Rock GA, Shumak KH, Buskard NA, et al. Comparison of plasma exchange with plasma infusion in the treatment of thrombotic thrombocytopenic purpura. Canadian Apheresis Study Group. N Engl J Med. 1991; 325(6):393-397. [PubMed: 2062330]

16. Delvaeye M, Noris M, De Vriese A, et al. Thrombomodulin mutations in atypical hemolyticuremic syndrome. N Engl J Med. 2009; 361(4):345-357. [PubMed: 19625716]

17. Noris M, Remuzzi G. Atypical hemolytic-uremic syndrome. N Engl J Med. 2009; 361(17):16761687. [PubMed: 19846853]

18. Kwon T, Dragon-Durey MA, Macher MA, et al. Successful pre-transplant management of a patient with anti-factor $\mathrm{H}$ autoantibodies-associated haemolytic uraemic syndrome. Nephrol Dial Transplant. 2008; 23(6):2088-2090. [PubMed: 18326881]

19. Levi M, Ten Cate H. Disseminated intravascular coagulation. N Engl J Med. 1999; 341(8):586592. [PubMed: 10451465]

20. Levi M. Current understanding of disseminated intravascular coagulation. Br J Haematol. 2004; 124(5):567-576. [PubMed: 14871243]

21. Churchwell KB, McManus ML, Kent P, et al. Intensive blood and plasma exchange for treatment of coagulopathy in meningococcemia. J Clin Apher. 1995; 10(4):171-177. [PubMed: 8770708]

22. Niewold TB, Bundrick JB. Disseminated intravascular coagulation due to cytomegalovirus infection in an immunocompetent adult treated with plasma exchange. Am J Hematol. 2006; 81(6):454-457. [PubMed: 16680750]

23. Stegmayr BG, Banga R, Berggren L, Norda R, Rydvall A, Vikerfors T. Plasma exchange as rescue therapy in multiple organ failure including acute renal failure. Crit Care Med. 2003; 31(6):1730 1736. [PubMed: 12794412]

24. van Deuren M, Frieling JT, van der Ven-Jongekrijg J, et al. Plasma patterns of tumor necrosis factor-alpha (TNF) and TNF soluble receptors during acute meningococcal infections and the effect of plasma exchange. Clin Infect Dis. 1998; 26(4):918-923. [PubMed: 9564476]

25. Nguyen TC, Han YY, Kiss JE, et al. Intensive plasma exchange increases a disintegrin and metalloprotease with thrombospondin motifs-13 activity and reverses organ dysfunction in children with thrombocytopenia-associated multiple organ failure*. Crit Care Med. 2008; 36(10): 2878-2887. [PubMed: 18828196]

26. Nadel S, Goldstein B, Williams MD, et al. Drotrecogin alfa (activated) in children with severe sepsis: a multicentre phase III randomised controlled trial. The Lancet. 2007; 369(9564):836-843.

27. Asherson RA, Cervera R, de Groot PG, et al. Catastrophic antiphospholipid syndrome: international consensus statement on classification criteria and treatment guidelines. Lupus. 2003; 12(7):530-534. [PubMed: 12892393] 
28. Cervera R, Font J, Gomez-Puerta JA, et al. Validation of the preliminary criteria for the classification of catastrophic antiphospholipid syndrome. Ann Rheum Dis. 2005; 64(8):12051209. [PubMed: 15708888]

29. Flamholz R, Tran T, Grad GI, et al. Therapeutic plasma exchange for the acute management of the catastrophic antiphospholipid syndrome: beta(2)-glycoprotein I antibodies as a marker of response to therapy. J Clin Apher. 1999; 14(4):171-176. [PubMed: 10611626]

30. Cervera R, Bucciarelli S, Plasin MA, et al. Catastrophic antiphospholipid syndrome (CAPS): descriptive analysis of a series of 280 patients from the "CAPS Registry". J Autoimmun. 2009; 32(3-4):240-245. [PubMed: 19324520]

31. Uthman I, Shamseddine A, Taher A. The role of therapeutic plasma exchange in the catastrophic antiphospholipid syndrome. Transfus Apher Sci. 2005; 33(1):11-17. [PubMed: 15951243]

32. Ruutu T, Barosi G, Benjamin RJ, et al. Diagnostic criteria for hematopoietic stem cell transplantassociated microangiopathy: results of a consensus process by an International Working Group. Haematologica. 2007; 92(1):95-100. [PubMed: 17229640]

33. Uderzo C, Bonanomi S, Busca A, et al. Risk factors and severe outcome in thrombotic microangiopathy after allogeneic hematopoietic stem cell transplantation. Transplantation. 2006; 82(5):638-644. [PubMed: 16969286]

34. George JN, Li X, McMinn JR, Terrell DR, Vesely SK, Selby GB. Thrombotic thrombocytopenic purpura-hemolytic uremic syndrome following allogeneic HPC transplantation: a diagnostic dilemma. Transfusion. 2004; 44(2):294-304. [PubMed: 14962323]

35. Elliott MA, Nichols WL Jr, Plumhoff EA, et al. Posttransplantation thrombotic thrombocytopenic purpura: a single-center experience and a contemporary review. Mayo Clin Proc. 2003; 78(4):421430. [PubMed: 12683694]

36. Siami K, Kojouri K, Swisher KK, Selby GB, George JN, Laszik ZG. Thrombotic microangiopathy after allogeneic hematopoietic stem cell transplantation: an autopsy study. Transplantation. 2008; 85(1):22-28. [PubMed: 18192907]

37. Kennedy GA, Kearey N, Bleakley S, Butler J, Mudie K, Durrant S. Transplantation-associated thrombotic microangiopathy: effect of concomitant GVHD on efficacy of therapeutic plasma exchange. Bone Marrow Transplant. 2010; 45(4):699-704. [PubMed: 19767787]

38. Oran B, Donato M, Aleman A, et al. Transplant-associated microangiopathy in patients receiving tacrolimus following allogeneic stem cell transplantation: risk factors and response to treatment. Biol Blood Marrow Transplant. 2007; 13(4):469-477. [PubMed: 17382253]

39. Christidou F, Athanasiadou A, Kalogiannidis P, et al. Therapeutic plasma exchange in patients with grade 2-3 hematopoietic stem cell transplantation-associated thrombotic thrombocytopenic purpura: a ten-year experience. Ther Apher Dial. 2003; 7(2):259-262. [PubMed: 12918953]

40. Zakarija A, Kwaan HC, Moake JL, et al. Ticlopidine- and clopidogrel-associated thrombotic thrombocytopenic purpura (TTP): review of clinical, laboratory, epidemiological, and pharmacovigilance findings (1989-2008). Kidney Int Suppl. 2009; 112:S20-S24. [PubMed: 19180126]

41. Bennett CL, Kim B, Zakarija A, et al. Two mechanistic pathways for thienopyridine-associated thrombotic thrombocytopenic purpura: a report from the SERF-TTP Research Group and the RADAR Project. J Am Coll Cardiol. 2007; 50(12):1138-1143. [PubMed: 17868804]

42. Naseer N, Aijaz A, Saleem MA, Nelson J, Peterson SJ, Frishman WH. Ticlopidine-associated thrombotic thrombocytopenic purpura. Heart Dis. 2001; 3(4):221-223. [PubMed: 11975797]

43. Pham PT, Peng A, Wilkinson AH, et al. Cyclosporine and tacrolimus-associated thrombotic microangiopathy. Am J Kidney Dis. 2000; 36(4):844-850. [PubMed: 11007689]

44. Au WY, Lie AK, Lam CC, et al. Tacrolimus (FK 506) induced thrombotic thrombocytopenic purpura after $\mathrm{ABO}$ mismatched second liver transplantation: salvage with plasmapheresis and prostacyclin. Haematologica. 2000; 85(6):659-662. [PubMed: 10870125]

45. Gupta S, Ttan N, Topolsky D, et al. Thrombotic thrombocytopenic purpura induced by cyclosporin a after allogeneic bone marrow transplantation treated by red blood cell exchange transfusion: a case report. Am J Hematol. 2005; 80(3):246-247. [PubMed: 16247749] 
46. Nakazawa Y, Hashikura Y, Urata K, et al. Von Willebrand factor--cleaving protease activity in thrombotic microangiopathy after living donor liver transplantation: a case report. Liver Transpl. 2003; 9(12):1328-1333. [PubMed: 14625834]

47. Bambauer R, Schwarze U, Schiel R. Cyclosporin A and therapeutic plasma exchange in the treatment of severe systemic lupus erythematosus. Artif Organs. 2000; 24(11):852-856. [PubMed: 11119071]

48. Neuwelt CM. The role of plasmapheresis in the treatment of severe central nervous system neuropsychiatric systemic lupus erythematosus. Ther Apher Dial. 2003; 7(2):173-182. [PubMed: 12918940]

49. Schroeder JO, Euler HH. Treatment combining plasmapheresis and pulse cyclophosphamide in severe systemic lupus erythematosus. Adv Exp Med Biol. 1989; 260:203-213. [PubMed: 2624244]

50. Canas C, Tobon GJ, Granados M, Fernandez L. Diffuse alveolar hemorrhage in Colombian patients with systemic lupus erythematosus. Clin Rheumatol. 2007; 26(11):1947-1949. [PubMed: 17377738]

51. Wei N, Klippel JH, Huston DP, et al. Randomised trial of plasma exchange in mild systemic lupus erythematosus. Lancet. 1983; 1(8314-5):17-22. [PubMed: 6129368]

52. Hanly JG, Hong C, Zayed E, Jones JV, Jones E. Immunomodulating effects of synchronised plasmapheresis and intravenous bolus cyclophosphamide in systemic lupus erythematosus. Lupus. 1995; 4(6):457-463. [PubMed: 8749568]

53. Ferenci P. Pathophysiology and clinical features of Wilson disease. Metab Brain Dis. 2004; 19(34):229-239. [PubMed: 15554419]

54. Asfaha S, Almansori M, Qarni U, Gutfreund KS. Plasmapheresis for hemolytic crisis and impending acute liver failure in Wilson disease. J Clin Apher. 2007; 22(5):295-298. [PubMed: 17880018]

55. Hursitoglu M, Kara O, Cikrikcioglu MA, Celepkulu T, Aydin S, Tukek T. Clinical improvement of a patient with severe Wilson's disease after a single session of therapeutic plasma exchange. J Clin Apher. 2009; 24(1):25-27. [PubMed: 19156772]

56. Jhang JS, Schilsky ML, Lefkowitch JH, Schwartz J. Therapeutic plasmapheresis as a bridge to liver transplantation in fulminant Wilson disease. J Clin Apher. 2007; 22(1):10-14. [PubMed: 17285615]

57. Kiss JE, Berman D, Van Thiel D. Effective removal of copper by plasma exchange in fulminant Wilson's disease. Transfusion. 1998; 38(4):327-331. [PubMed: 9595013]

58. Nagata Y, Uto H, Hasuike S, et al. Bridging use of plasma exchange and continuous hemodiafiltration before living donor liver transplantation in fulminant Wilson's disease. Intern Med. 2003; 42(10):967-970. [PubMed: 14606709]

59. Lee WM. Acute liver failure. Semin Respir Crit Care Med. 2012; 33(1):36-45. [PubMed: 22447259]

60. Clemmesen JO, Kondrup J, Nielsen LB, Larsen FS, Ott P. Effects of high-volume plasmapheresis on ammonia, urea, and amino acids in patients with acute liver failure. Am J Gastroenterol. 2001; 96(4):1217-1223. [PubMed: 11316173]

61. Ahboucha S, Gamrani H, Baker G. GABAergic neurosteroids: The "endogenous benzodiazepines" of acute liver failure. Neurochem Int. 2011

62. Akdogan M, Camci C, Gurakar A, et al. The effect of total plasma exchange on fulminant hepatic failure. J Clin Apher. 2006; 21(2):96-99. [PubMed: 16142721]

63. De Silvestro G, Marson P, Brandolese R, Pittoni G, Ongaro G. A single institution's experience (1982-1999) with plasma-exchange therapy in patients with fulminant hepatic failure. Int J Artif Organs. 2000; 23(7):454-461. [PubMed: 10941639]

64. Singer AL, Olthoff KM, Kim H, Rand E, Zamir G, Shaked A. Role of plasmapheresis in the management of acute hepatic failure in children. Ann Surg. 2001; 234(3):418-424. [PubMed: 11524594]

65. Rydberg L. ABO-incompatibility in solid organ transplantation. Transfus Med. 2001; 11(4):325342. [PubMed: 11532188] 
66. Roche SL, Burch M, O'Sullivan J, et al. Multicenter experience of ABO-incompatible pediatric cardiac transplantation. Am J Transplant. 2008; 8(1):208-215. [PubMed: 18021280]

67. West LJ, Pollock-Barziv SM, Dipchand AI, et al. ABO-incompatible heart transplantation in infants. N Engl J Med. 2001; 344(11):793-800. [PubMed: 11248154]

68. Carithers RL Jr. Liver transplantation. American Association for the Study of Liver Diseases. Liver Transpl. 2000; 6(1):122-135. [PubMed: 10648593]

69. Winters JL, Gloor JM, Pineda AA, Stegall MD, Moore SB. Plasma exchange conditioning for ABO-incompatible renal transplantation. J Clin Apher. 2004; 19(2):79-85. [PubMed: 15274200]

70. Tobian AA, Shirey RS, Montgomery RA, Tisch DJ, Ness PM, King KE. Therapeutic plasma exchange reduces $\mathrm{ABO}$ titers to permit $\mathrm{ABO}$-incompatible renal transplantation. Transfusion. 2009; 49(6):1248-1254. [PubMed: 19210321]

71. Khurana DS, Melvin JJ, Kothare SV, et al. Acute disseminated encephalomyelitis in children: discordant neurologic and neuroimaging abnormalities and response to plasmapheresis. Pediatrics. 2005; 116(2):431-436. [PubMed: 16061599]

72. Lin CH, Jeng JS, Yip PK. Plasmapheresis in acute disseminated encephalomyelitis. J Clin Apher. 2004; 19(3):154-159. [PubMed: 15493052]

73. RamachandranNair R, Rafeequ M, Girija AS. Plasmapheresis in childhood acute disseminated encephalomyelitis. Indian Pediatr. 2005; 42(5):479-482. [PubMed: 15923696]

74. Garg RK. Acute disseminated encephalomyelitis. Postgrad Med J. 2003; 79(927):11-17. [PubMed: 12566545]

75. Kaynar L, Altuntas F, Aydogdu I, et al. Therapeutic plasma exchange in patients with neurologic diseases: retrospective multicenter study. Transfus Apher Sci. 2008; 38(2):109-115. [PubMed: 18331814]

76. Keegan M, Pineda AA, McClelland RL, Darby CH, Rodriguez M, Weinshenker BG. Plasma exchange for severe attacks of CNS demyelination: predictors of response. Neurology. 2002; 58(1):143-146. [PubMed: 11781423]

77. Menge T, Hemmer B, Nessler S, et al. Acute disseminated encephalomyelitis: an update. Arch Neurol. 2005; 62(11):1673-1680. [PubMed: 16286539]

78. Johnson JP, Moore J Jr, Austin HA 3rd, Balow JE, Antonovych TT, Wilson CB. Therapy of antiglomerular basement membrane antibody disease: analysis of prognostic significance of clinical, pathologic and treatment factors. Medicine (Baltimore). 1985; 64(4):219-227. [PubMed: 3892220]

79. Levy JB, Turner AN, Rees AJ, Pusey CD. Long-term outcome of anti-glomerular basement membrane antibody disease treated with plasma exchange and immunosuppression. Ann Intern Med. 2001; 134(11):1033-1042. [PubMed: 11388816]

80. Simpson IJ, Doak PB, Williams LC, et al. Plasma exchange in Goodpasture's syndrome. Am J Nephrol. 1982; 2(6):301-311. [PubMed: 6762091]

81. Lazor R, Bigay-Game L, Cottin V, et al. Alveolar hemorrhage in anti-basement membrane antibody disease: a series of 28 cases. Medicine (Baltimore). 2007; 86(3):181-193. [PubMed: 17505257]

82. Zauner I, Bach D, Braun N, et al. Predictive value of initial histology and effect of plasmapheresis on long-term prognosis of rapidly progressive glomerulonephritis. Am J Kidney Dis. 2002; 39(1): 28-35. [PubMed: 11774098]

83. Little MA, Pusey CD. Rapidly progressive glomerulonephritis: current and evolving treatment strategies. J Nephrol. 2004; 17(Suppl 8):S10-S19. [PubMed: 15599880]

84. Frasca GM, Soverini ML, Falaschini A, Tampieri E, Vangelista A, Stefoni S. Plasma exchange treatment improves prognosis of antineutrophil cytoplasmic antibody-associated crescentic glomerulonephritis: a case-control study in 26 patients from a single center. Ther Apher Dial. 2003; 7(6):540-546. [PubMed: 15018241]

85. Klemmer PJ, Chalermskulrat W, Reif MS, Hogan SL, Henke DC, Falk RJ. Plasmapheresis therapy for diffuse alveolar hemorrhage in patients with small-vessel vasculitis. Am J Kidney Dis. 2003; 42(6):1149-1153. [PubMed: 14655185]

86. de Lind van Wijngaarden RA, Hauer HA, Wolterbeek R, et al. Clinical and histologic determinants of renal outcome in ANCA-associated vasculitis: A prospective analysis of 100 patients with severe renal involvement. J Am Soc Nephrol. 2006; 17(8):2264-2274. [PubMed: 16825335] 
87. Jayne DR, Gaskin G, Rasmussen N, et al. Randomized trial of plasma exchange or high-dosage methylprednisolone as adjunctive therapy for severe renal vasculitis. J Am Soc Nephrol. 2007; 18(7):2180-2188. [PubMed: 17582159]

88. Henter JI, Horne A, Arico M, et al. HLH-2004: Diagnostic and therapeutic guidelines for hemophagocytic lymphohistiocytosis. Pediatr Blood Cancer. 2007; 48(2):124-131. [PubMed: 16937360]

89. Jordan MB, Allen CE, Weitzman S, Filipovich AH, McClain KL. How I treat hemophagocytic lymphohistiocytosis. Blood. 2011; 118(15):4041-4052. [PubMed: 21828139]

90. Castillo L, Carcillo J. Secondary hemophagocytic lymphohistiocytosis and severe sepsis/ systemic inflammatory response syndrome/multiorgan dysfunction syndrome/macrophage activation syndrome share common intermediate phenotypes on a spectrum of inflammation. Pediatr Crit Care Med. 2009; 10(3):387-392. [PubMed: 19325510]

91. Coman T, Dalloz MA, Coolen N, et al. Plasmapheresis for the treatment of acute pancreatitis induced by hemophagocytic syndrome related to hypertriglyceridemia. J Clin Apher. 2003; 18(3): 129-131. [PubMed: 14569604]

92. Imashuku S, Hibi S, Ohara T, et al. Effective control of Epstein-Barr virus-related hemophagocytic lymphohistiocytosis with immunochemotherapy. Histiocyte Society. Blood. 1999; 93(6):1869_ 1874. [PubMed: 10068659]

93. Ladisch S, Ho W, Matheson D, Pilkington R, Hartman G. Immunologic and clinical effects of repeated blood exchange in familial erythrophagocytic lymphohistiocytosis. Blood. 1982; 60(4): 814-821. [PubMed: 7115950]

94. Nakakura H, Ashida A, Matsumura H, et al. A case report of successful treatment with plasma exchange for hemophagocytic syndrome associated with severe systemic juvenile idiopathic arthritis in an infant girl. Ther Apher Dial. 2009; 13(1):71-76. [PubMed: 19379173]

95. Raschke RA, Garcia-Orr R. Hemophagocytic lymphohistiocytosis: a potentially underrecognized association with systemic inflammatory response syndrome, severe sepsis, and septic shock in adults. Chest. 2011; 140(4):933-938. [PubMed: 21737492]

96. Sanada S, Ookawara S, Shindo T, Morino K, Ishikawa H, Suzuki M. A case report of the effect of plasma exchange on reactive hemophagocytic syndrome associated with toxic shock syndrome. Ther Apher Dial. 2004; 8(6):503-506. [PubMed: 15663552]

97. Satomi A, Nagai S, Nagai T, et al. Effect of plasma exchange on refractory hemophagocytic syndrome complicated with myelodysplastic syndrome. Ther Apher. 1999; 3(4):317-319. [PubMed: 10608726]

98. Song KS, Sung HJ. Effect of plasma exchange on the circulating IL-6 levels in a patient with fatal hemophagocytic syndrome associated with bile ductopenia. Ther Apher Dial. 2006; 10(1):87-89. [PubMed: 16556142]

99. Zhang XY, Ye XW, Feng DX, Han J, Li D, Zhang C. Hemophagocytic Lymphohistiocytosis Induced by Severe Pandemic Influenza A (H1N1) 2009 Virus Infection: A Case Report. Case Report Med. 2011; 2011:951910. [PubMed: 21559246]

100. Demirkol D, Yildizdas D, Bayrakci B, et al. Hyperferritinemia in the critically ill child with secondary HLH/sepsis/MODS/MAS: what is the treatment? Critical Care. 2012; 16(2):R52. [PubMed: 22715953] 